\title{
MA Empirical Analysis Based on the Cloud Computing Sector of
}

\section{Listed Companies}

\author{
Zhi-heng Lin ${ }^{\mathrm{a}}$, Xiao-ming Huang ${ }^{\mathrm{b},{ }^{*}}$ and Pin Wang ${ }^{\mathrm{c}}$ \\ Mathematics and Information Science Department, Guangxi College of \\ Education, Nanning 530023, Guangxi, China \\ bhxm6021@sina.com \\ Corresponding author: Xiao-Ming HUANG
}

Keywords: Cloud computing sector, MA, Empirical analysis.

\begin{abstract}
With the method of statistical empirical analysis, This study aims to test the MA expert system via securities trading software according to authentic and open securities cloud computing sector data. By taking the annual net profit margin, rate of return and win rate as the management goal, the MA index is analyzed empirically. The annual rate of return and net profit margin of MA expert system are $47.38 \%$ and $47.42 \%$ of Shanghai securities composite index, suggesting the guidance of cloud computing sector investment by MA expert system cannot outperform the market index. $43.16 \%$ winning rate of MA expert system also indicates that the system risk for investors is huge. 8.89\% annual rate of return is 5.08 times that of the one-year interest rate of bank deposit. Apparently, the results are just-so-so. Considering the low annual rate of return of MA expert system, the system is not an attractive investment scheme for the investors.
\end{abstract}

\section{Introduction}

Technical analysis is a method of securities investment which aims to predict the market price change direction via the analysis of market behaviors, that is, graphs or diagrams are drawn according to the time sequence, or certain index systems are formed for the daily transaction state of the stock market, including the price change, transaction volume, and open interest changes. Then, analytical researches are carried out specific to these graphs, diagrams or index system, so as to predict the stock price trend. Due to the prevalence of computer use, securities analyses and transactions of all securities investors can be completed by computer. Currently, there's a common expert system MA among securities analysis software. It is generally known as the moving average system, the design of which is based on the theory "average cost concept" of Dow Jones. By taking the winning rate, annual rate of return, and net profit margin as the objective goal, this paper is to test the cloud computing sector of listed companies and elaborate the practicability of MA system with statistical methods.

Due to the limitation of the length of the paper, relevant studies on expert system MA are not repeated hereby.

The formula of the moving average Ma [1] is:

$$
M A=\frac{c_{1}+c_{2}+\mathrm{L} \mathrm{L}+c_{n}}{n}
$$


Where, $c_{i}(i=1,2, \mathrm{~L} n)$ is the $\mathrm{i}$-th day of closing price, and $n$ is the moving average cycle.

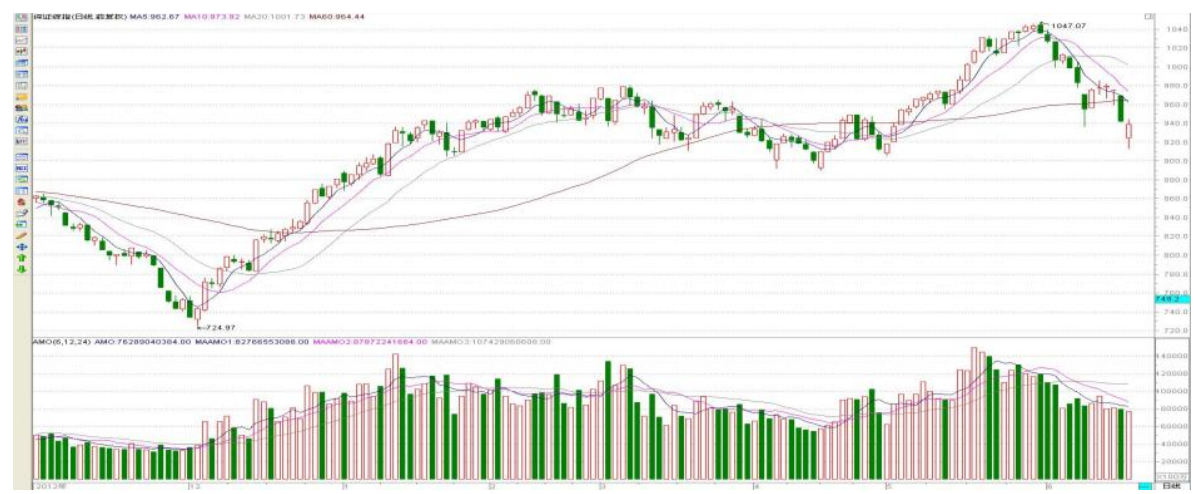

Fig.1 MA expert system

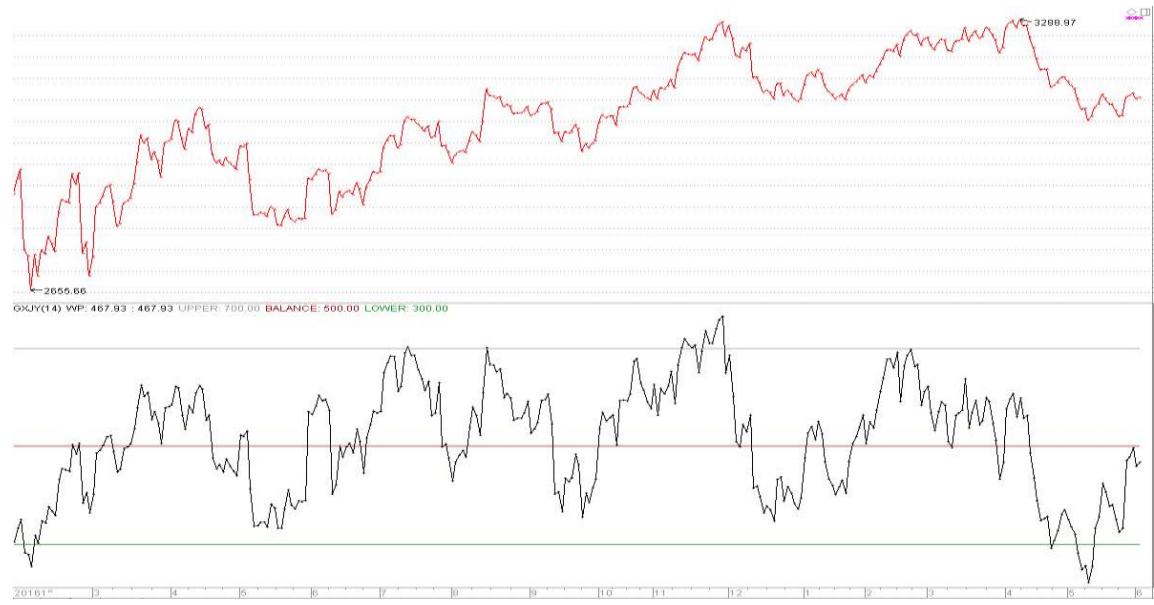

Fig.2 Shanghai securities composite index

\section{Empirical analysis of MA expert system (see Fig.1)}

\section{Experiment and result}

(1) Experimental program:

The expert system MA is developed in accordance with Granville's eight rules. The transaction rule is: MA(10) line is added to MA(5) line to form the golden cross buy-in. $\mathrm{MA}(30)$ line is destroyed by MA(10) line to form the death cross sell-out [2].

Source code of the MA expert system

SHORT 1305

LONG 510030

CROSS(MA(CLOSE,SHORT),MA(CLOSE,LONG))

CROSS(MA(CLOSE,LONG),MA(CLOSE,SHORT))

ENTERLONG:CROSS(MA(CLOSE,SHORT),MA(CLOSE,LONG));

EXITLONG:CROSS(MA(CLOSE,LONG),MA(CLOSE,SHORT))

(2) Experimental platform: V5.99 of the great wisdom securities information platform

(3) Experimental parameters: one-time position building or full liquidation of funds meeting conditions, taking $0.5 \%$ of transaction costs.

(4) Experimental samples: date line data of the cloud computing block (March 2016 - April 2017)

(5) Experimental process, time and results: 
Table1 Test results of MA expert system

Test method: technical index - MA

System test setting

Test time: March 1, 2016 - April 11, 2017 Calculation of the forced liquidation

Test stock: 57 in total Initial input: 40,000.00yuan

Buy-in conditions:

One of the following conditions is valid:

1. The following conditions are valid at the same time

1.1 Technical index: MA (5, 10, 20, 30, 120, 250) indicatrix MA1 crosses upward MA2 [moving average]

When conditions are valid: according to the middle price, buy in with all funds at the closing price

In case of continuous signals: no more buy-in

Sell-out conditions: no sell-out condition

Liquidation conditions: (close a position according to the closing price)

Index-based stock selection: technical index: MA $(5,10,20,30,120,250)$ indicatrix MA2 crosses downward MA3 [moving average]

Number of tested stocks: 57

Annual rate of return: $8.89 \%$

Winning rate: $43.16 \%$

System test report summaries

Average profit: 589.01yuan

Annual transaction times: 344.31

Success rate: $42.71 \%$

Annual signal number: 692.31

Maximum single profit: 18,105.90yuan Maximum single loss: -16,139.78yuan

Transaction times: $373 \quad$ Profitable transaction times: 161 (accounting for 43.16\%)

Net profit: 219,701.50yuan

Net profit rate: $9.64 \%$

Simple possessed net profit: $178,446.41 \quad$ Simple possessed net profit margin: $7.83 \%$

Ideal model net profit: $27,285,252,096.00 y u a n$

Ideal model net profit rate: $1,196,721.63 \%$

Number of tested stocks: 57

Net profit: $219,701.50 y u a n$

Total earnings: 660,352.69yuan

Transaction times: 373

Annual transaction times: 344.31

Transaction sum: 14,722,923.00yuan

Maximum single earnings: 18,105.90yuan

Average earnings: 1,770.38yuan

Average profit: 589.01yuan

Maximum continuous earning times: 5

Average transaction period: 26.19

Average transaction earning period: 30.14

Earning coefficient: 0.20

Maximum floating earnings: 2,481,812.75yuan Maximum floating losses: 0.00yuan

Maximum floating earning and loss difference: $2,481,812.75 y u a n$

Total input: 2,280,000.00yuan

Buy-in signal statistics

(Make statistics of the situation of all buy-in signal points without considering signal deletion caused by funds and strategies in the transaction test)

Success rate: $42.71 \%$

Signal number: 377
Net profit margin: $9.64 \%$

Total losses: $-440,651.03$ yuan

Winning rate: $43.16 \%$

Earning / loss transaction times: 161/212

Transaction fee: 21,950.86yuan

Maximum single losses: $-16,139.78$ yuan

Average losses: -1,181.37yuan

Average earnings / Average losses: -149.86

Maximum continuous loss times: 16

Average transaction loss period: 23.19 


\section{Result analysis}

Table2 Comparative analysis sheet

\begin{tabular}{|c|c|c|c|c|}
\hline & Winning rate & $\begin{array}{c}\text { Annual rate of } \\
\text { return }\end{array}$ & $\begin{array}{c}\text { Net profit } \\
\text { margin }\end{array}$ & $\begin{array}{c}\text { Annual transaction } \\
\text { times }\end{array}$ \\
\hline MA expert system & 43.16 & 8.89 & 9.64 & 344.31 \\
\hline $\begin{array}{c}\text { Shanghai securities } \\
\text { composite index }\end{array}$ & & 18.76 & 20.33 & \\
\hline $\begin{array}{c}\text { Ratio of MA results and } \\
\text { Shanghai securities } \\
\text { composite index results }\end{array}$ & & $47.38 \%$ & $47.42 \%$ & \\
\hline
\end{tabular}

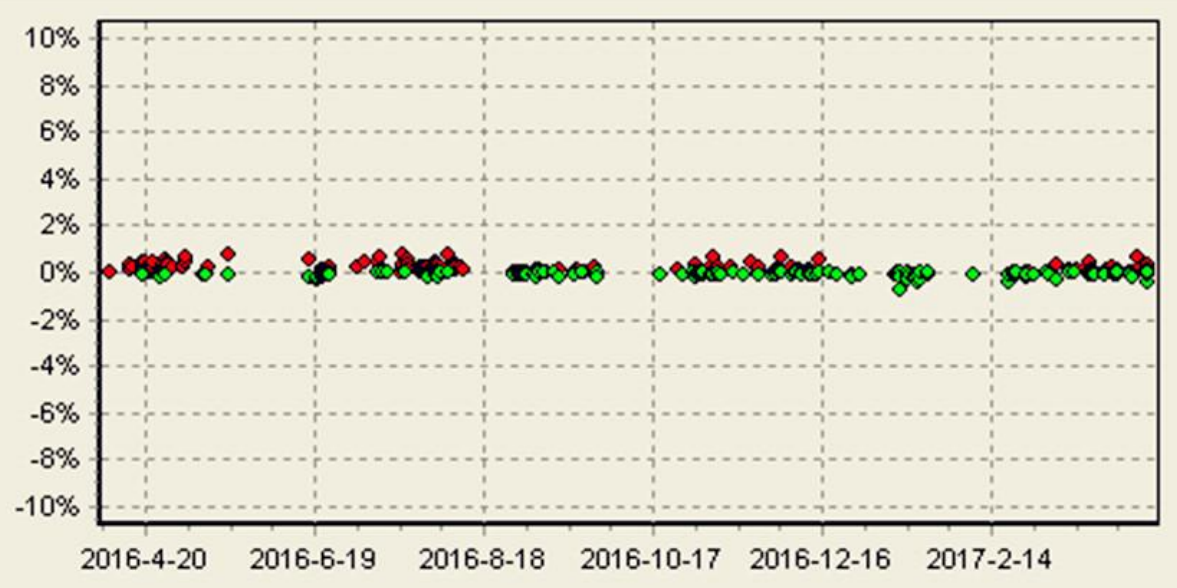

Fig.3 Annual MA transaction times

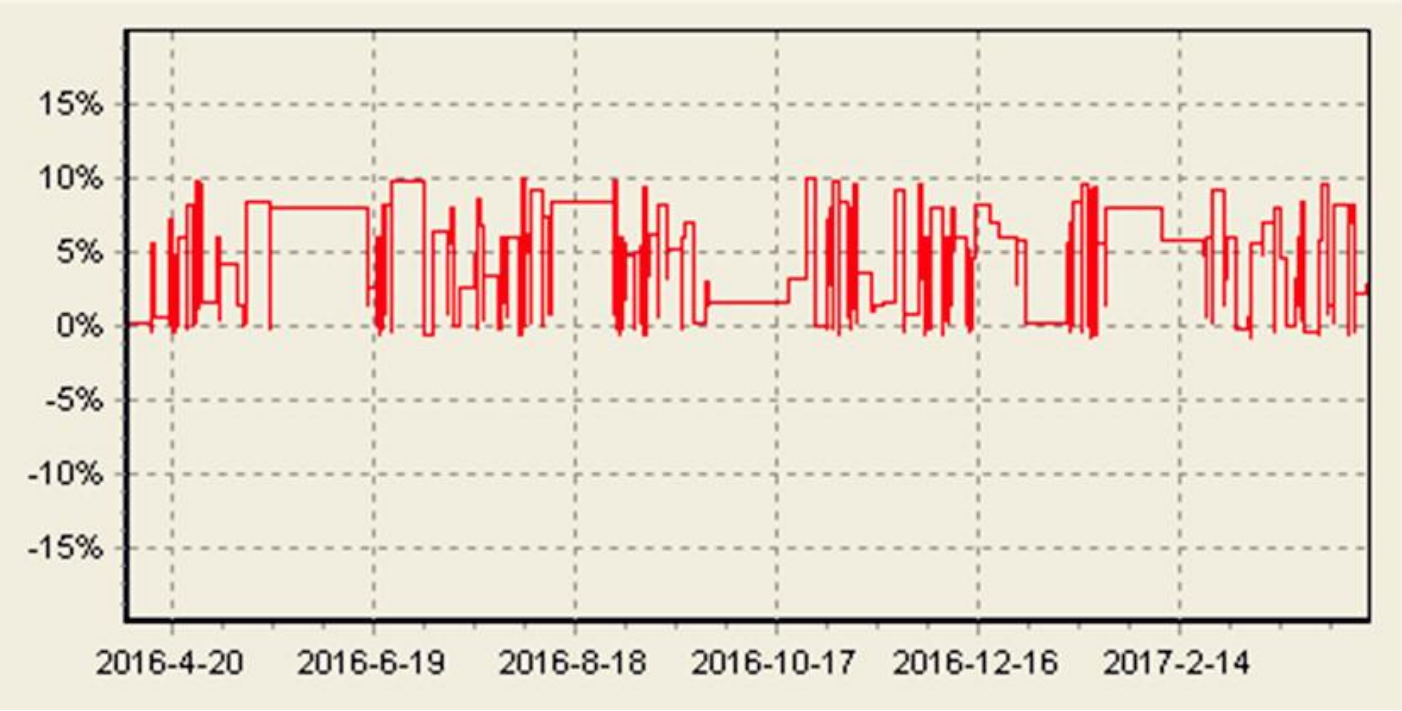

Fig.4 MA earnings curve

\section{Conclusions}

By taking the winning rate, annual rate of return and net profit margin that are concerned most by investors as the management goal [3-4], the practicability of MA expert system is 
analyzed. The annual rate of return and net profit margin of MA expert system are $47.38 \%$ and $47.42 \%$ of Shanghai securities composite index, suggesting it is impossible for MA expert system to outperform the market index by guiding the cloud computing sector investment. $43.16 \%$ winning rate of MA expert system also indicates the system risk is huge for investors. For investors hating risks, this investment scheme is obviously not a favorable choice. $8.89 \%$ annual rate of return is 5.08 times of $1.75 \%$ one-year interest rate of bank deposit, the result of which is apparently just-so-so. Thus, it is risky to apply MA expert system to the cloud computing sector for investment guidance. Furthermore, as can be seen from the graphical indicator of the MA expert system in Fig.1, frequent transaction (with the annual transaction times as high as 344.31 times) is the main reason for risks. Considering to low annual rate of return, MA expert system is not an attractive investment scheme for any investors.

\section{Acknowledgement}

This research was financially supported by the Education Department of Guangxi Province (NO.KY2016YB579), and scientific research projects of Guangxi College of Education in 2015 (NO.A2015001,NO.B2015001,NO.B2015006), and 2017 Key Program for Education and Teaching Reform of Guangxi College of Education (NO.XJJG17A09).

\section{References}

[1] Information on http://en.wikipedia.org/wiki/Moving_average

[2] Information on http://en.wikipedia.org/wiki/Moving_average

[3] Y. Liu, Empirical Study on Senior Managers and Performances in Companies of High-Tech based on SPSS Software Regression Analysis, Journal of software. 7(2012)1569-1576.

[4] Y.M.Wang, Application of Moving Average in Stock Market, Zhejiang Statistics(in Chinese). 2(1998)27-28. 